\title{
CLOSING THE GAP: UNDERSTANDING MEDIA REPORTING ON HIV/AIDS
}

\author{
Richard Delate \\ Manager, AIDS Development Research and Evaluation (ADRE)
}

The South African media are often accused of not giving enough attention to HIV/AIDS. Research by Media Tenor undertaken from 1 January to 31 December 2002 in which 148056 reports were analysed from selected South African media found that HIVIAIDS received just under $3 \%$ of all media coverage, representing more coverage than issues such as education, health and even the environment but less than business, crime and politics.

Warren Parker and Kevin Kelly of the Centre for AIDS Development Research and Evaluation (CADRE) pointed out at a recent presentation to the South African National Editors Forum (SANEF) that media reporting has intensified over time and has tended to follow the important emerging themes in South Africa. These include following political debates, tracking issues such as prevention of mother-tochild transmission, introduction of drug therapies, relating the epidemic to economic issues, impacts and responses at family and community level, and critical reporting on various fronts.

These trends are reflected in the research done by Media Tenor, which shows that in 2002,32.5\% of media articles on HIV/AIDS were related to treatment, of which $45 \%$ were concerned with nevirapine. Prevention received $25.3 \%$ of the coverage but the predominant topic in this category, $65 \%$, concerned the social and political will to confront the epidemic.

While statistics are important in giving us a picture of the commitment of the media to covering the epidemic, and what issues the media are covering, they do not provide a good indication of the quality or depth of media reporting on the topic.

\section{HIV/AIDS ISSUES REPORTED UPON BY THE SA MEDIA} IN 2002

$\begin{array}{lc}\text { HIV/AIDS issue } & \% \text { of coverage } \\ \text { Treatment } & 32.5 \\ \text { Prevention } & 25.3 \\ \text { Social/political impact } & 20 \\ \text { Economic effects } & 4.5 \\ \text { Other } & 17.7 \\ \text { Source: Media Tenor, www.mediatenor.co.za } & \end{array}$

\section{QUALITY OF COVERAGE}

Anton Harber, Caxton Professor of Journalism at the University of the Witwatersrand, points out that newsrooms increasingly have 'fewer experienced journalists and more and more green generalists', which impacts negatively on the quality of coverage. Indeed nowhere is this more apparent than in the realm of media reporting on HIV/AIDS. South Africa does have some specialist reporters covering the topic - reporters who have educated themselves on the science of HIVIAIDS. But even these specialist journalists face constraints in covering the epidemic. They are expected to be experts in the bio-medical science of the epidemic, the demographic and economic impact, treatment, vaccines and social dimensions. As the epidemic unfolds and advances are made in addressing it, these journalists are required to keep abreast of current developments and for this they need resources to undertake research and access to experts who can provide them with insight to enable an in-depth and critical analysis of the issues as they unfold.

However, Harber notes that newsrooms are under-staffed, meaning that fewer journalists are available to cover more issues. In the case of HIVIAIDS, specialist reporters are also required to cover all issues relating to health. In some instances they have the added burden of covering other areas as assigned by the newsroom.

Harber highlights that the competitive nature of the industry and the need to demonstrate profits for shareholders and owners are resulting in cutbacks, including limiting the access of staff to the Internet and closing down internal libraries. These are the basic tools required by a journalist, and the cutbacks limit the ability of even specialist journalists to keep abreast with latest scientific developments.

Furthermore, editorial decision making has a great impact on the quality of coverage given to the epidemic. Peet Kruger, an editor with Beeld, indicated that at one point Beeld took the decision to cut down on the amount of reporting on HIV/AIDS owing to research that 


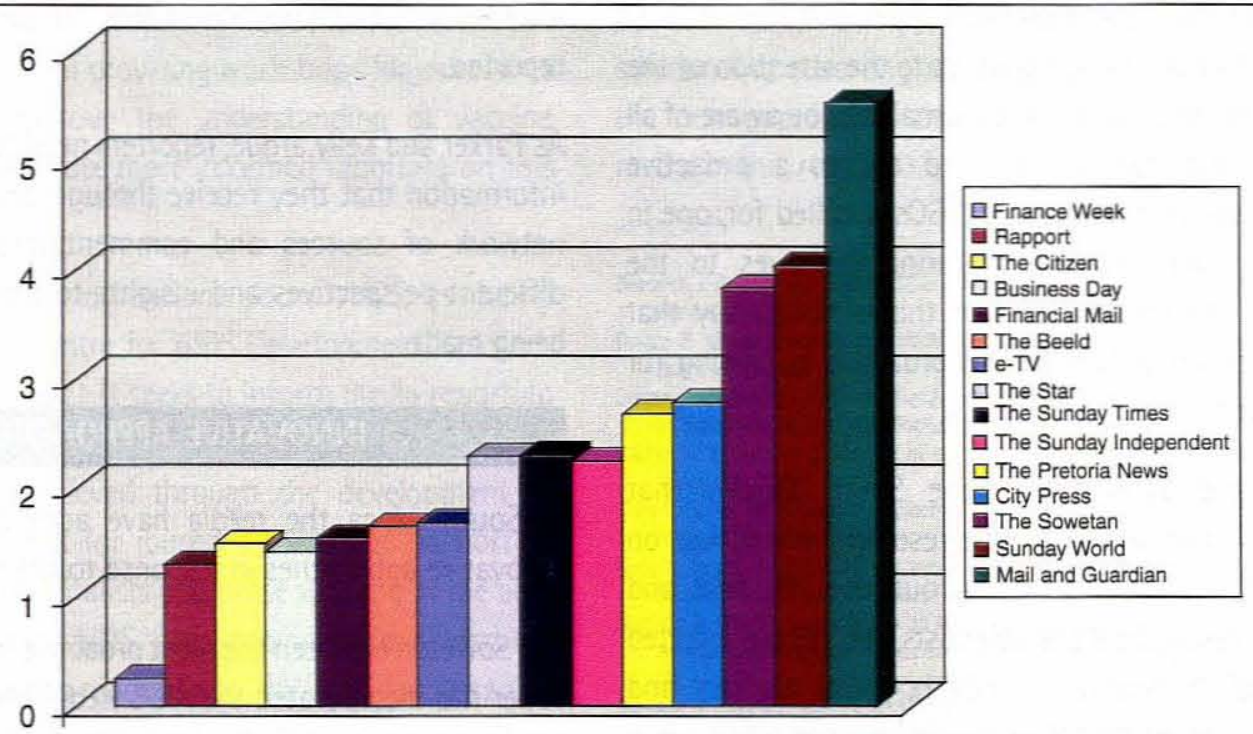

Media coverage of HIVIAIDS, 2002 (Source:Media Tenor, South Africa, 1 Jan - 31 Dec 2002 - www.mediatenor.co.za).

demonstrated 'audience fatigue with the topic'. Robyn Chalmers of Business Day says that their publication took the decision that reporting should focus on the relevance of the issue for business.

These editorial decisions limit the range of reporting and challenge journalists to find new and creative means of telling the story in the context of the editorial policy. But, as Claire Bisseker of the Financial Mail highlights, "how many times can one report on the potential impact of HIV/AIDS on the workforce, or the successful elements of workplace programmes, or the fact that it pays to treat with antiretrovirals?

It appears that HIVIAIDS is still confined to the specialist health reporter, and as such is viewed by the South African media as a health issue rather than a critical challenge that is at the centre of all economic and social development in the country. As such, it is imperative that reporters covering other beats should integrate HIV/AIDS into their own portfolios.

\section{BEYOND THE NEWSROOM}

Beyond the newsroom, there are many challenges confronting journalists that impact negatively on the quality of HIV/AIDS reporting, especially in relation to fairness and accuracy.

The Washington Post's Code of Ethics defines fairness as portraying both sides of the argument, while the African Women's Media Centre moves beyond this, saying that when it comes to HIV/AIDS journalists should also indicate which side carries more weight and why.

The relationship between government and the media with regard to reporting on HIV/AIDS has broken down to the extent that a journalist in KwaZulu-Natal described it as one of huge 'mistrust between government and particularly the ministry and the minister, and the media'.

This 'mistrust' has resulted in journalists deemed to be critical not being invited to press events, invitations being passed on to other journalists who are less likely to challenge the speakers, and complaints to the editors. A journalist from Mpumalanga says, 'When you do write anything, the flurry of denials, of press releases, the questioning of racial and political motivations of journalists who write about it - so there's a fair bit of tension.'

In addition, a Journ-AIDS survey of media experiences of spokespersons found that in most instances journalists revealed that government spokespersons were not responsive to requests for information, and would discuss issues only as long as these were off the record. However, the participants indicated that they also understood the constraints under which spokespersons operated, including the lack of clarity concerning government policy and the workload with which government spokespersons were burdened.

It is interesting to note that Media Tenor's research concluded that civil society had a significant voice $(34.5 \%)$ in the coverage of HIV/AIDS. Of these reports $7.9 \%$ were by NGOs including the TAC, $4 \%$ by South African doctors, and $3.2 \%$ by people living with HIVIAIDS.

In the Journ-AIDS survey, almost all respondents pointed out that the TAC was particularly effective in their media outreach. The reasons for this, according to the respondents, were that the TAC is proactive in communicating with the media, spokespersons were available at all times, and the TAC bought into the media logic and provides information to journalists that is packaged through the use of 'sound bytes'. 
This indicates that news does not happen in a vacuum - it is informed through bringing issues to the attention of the media. It is not possible for one journalist to be aware of all the issues that can be reported on, so a proactive partnership between media and NGOs is called for, one in which NGOs are proactive in bringing issues to the attention of the media. However, this is not to say that media themselves should be less proactive in looking for areas to cover.

Journalist and activist Charlene Smith argues that journalists 'should be doing more research, relying less on the Internet and more on going out into the field and meeting the researchers and scientists, and people infected and affected.' In relation to health, social workers and $\mathrm{NGOs,} \mathrm{Smith} \mathrm{argues} \mathrm{that} \mathrm{they} \mathrm{should} \mathrm{be} \mathrm{more} \mathrm{proactive} \mathrm{in}$ inviting the media to visit their projects and provide them with good information.

However, many organisations and indeed government are not proactive when it comes to dealing with the press. Many organisations do not understand what constitutes news, how decisions are made within the newsroom, or the newsgathering process. Many do not have a media strategy in place, or dedicated staff and personnel to work with the media. Often experts are reluctant to speak or take a 'belligerent' stance towards the media, rather than one that encourages reporting. In part this appears to be due to past experience, including being 'misquoted'.

How can we demand analytical, fair and accurate reporting if government, organisations and experts do not play an active role in communicating with the media?

\section{SENSATIONALISM SELLS}

Another aspect that speaks to the quality of reporting on HIV/AIDS is that of sensationalism. Indeed, NGOs and activists are quick to point to the media as sensationalising the issue. Yet, as indicated, the media in South Africa rely to a great extent on sources such as press releases and events that inform their reporting. This is not to deny that there is not a degree of sensationalism in the South African media that seeks to sell newspapers - but there is also no shortage of critics, researchers and HIVIAIDS organisations who habitually make use of sensationalism and are then quoted in the media.

A number of organisations and government employ public relations tactics with a view to 'selling the story to the media'. Indeed, just as we should demand that the media pursue and present the truth, so should we demand that organisations and agencies present us with factual and unbiased information, based on identifiable and verifiable information. It does not necessarily follow that a singlesourced press release should be published without alternative viewpoints, comments or perspectives being reported.

As Parker and Kelly argue, reporters need to interrogate the information that they receive through developing a wider network of sources and commentators that can add different perspectives and insights to the claims that are being made.

\section{INNOVATIVE APPROACHES}

In South Africa the media have adopted a number of innovative approaches in response to the epidemic.

The Sowetan has been the most proactive in this regard. The paper has incorporated the AIDS Red Ribbon as part of its masthead. It has a regular columnist, Lucky Mazibuko, who is living with HIV/AIDS. The popularity of Lucky's column is indicated by a number of letters from readers looking for advice or support. Other papers such as the Daily News and the Natal Witness also carry the red ribbon and AIDS helpline telephone number, together with their titles.

The Independent Newspapers Group prints a number of HIV/AIDS-related numbers with stories on HIV/AIDS, providing a point of reference if readers are looking for additional information. In addition the Group has concluded a partnership agreement with lovelife for the production of the ThetaNathi, a weekly youth supplement. In a similar vein the Sunday Times has also concluded a partnership agreement with lovelife for the production of S'camto Print. The SABC has a long tradition of partnering with NGOs for the production of programmatic content on HIVIAIDS. These include Soul City and loveLife. The SABC also commissions programming that is produced by consortia that include HIVIAIDS NGOs, while e-TV has worked with the TAC for the production of Beat-it, which combines personal documentary accounts of people living with HIV/AIDS with expert advice and explanation on strategies for living with HIV.

Similarly, a number of organisations are working to inform media reporting on HIVIAIDS.

Health-e is dedicated to producing news and analysis for print and electronic media regarding health policy and practice in South Africa. The agency employs some health journalists particularly experienced in reporting on HIVIAIDS. Articles are available through weekly newsbriefs and on the organisation's website - www.health-e.org.za.

More recently Wits University together with the Perinatal Research Unit at Chris Hani Baragwanath Hospital has started a research fellowship programme that undertakes research on media reporting on the epidemic, as a means to inform editorial decision making and projects working to improve media coverage. 
The South African AIDS Vaccine Initiative (SAAVI) has been engaged in a process of providing workshops for journalists in an effort to improve the understanding of vaccine research and to facilitate more informed reporting on this topic.

A research-based intervention, Journ-AIDS, is being undertaken by the Centre for AIDS Development Research and Evaluation (CADRE). It seeks to inform media reporting to ensure in-depth, accurate and critical reporting on HIV/AIDS. This is achieved through the development of information resources for journalists and the support of dialogue between journalists and those working in the area of HIVIAIDS. Journ-AIDS also provides in-newsroom training for journalists reporting on HIV/AIDS (endorsed by the South African National Editors Forum - SANEF) in partnership with a range of NGOs working in the area of HIVIAIDS.
In summary, this article outlines the complexity surrounding reporting on issues related to HIV/AIDS and the new approaches that have been undertaken by the media in this regard.

REFERENCES

Beamish J. Reporting on HIV/AIDS in Africa: A Manual. Senegal: African Women's Media Centre.

Delate R. Media reporting on HIVIAIDS in South Africa - going behind the statistics. Journ-AIDS 2003

Delate R. HIV/AIDS and the media: A discussion paper. Online lecture for the University of Natal and Washington, Bothell. (www.journ-aids.org).

Harber A. Journalism in the age of the market. 4th Harold Wolpe Memorial Lecture, 26 September 2002

Kelly K, Parker W. Writing the Epidemic: The Role of the South African Media in shaping response to HIV/AIDS. 2001

Kelly $\mathrm{K}$, Parker W. HIVIAIDS and media responses: Taking the lead. Presentation to the South African National Editors Forum, 2003 (www.journ-aids.org).

Manson H. Madiba leads nation on HIVIAIDS issues: coverage of HIVIAIDS in the South African Media: January - December 2002. Media Tenor SA Research Journal, 2003; 10 (4).

Manson H. HIVIAIDS and the SA Media: Charlene Smith takes media to task over HIVIAIDS coverage. Supplied by Media Tenor, South Africa, 2003.

Woshington Post. Media Bias Categories (www.eyeonthepost.org/bias, accessed 22 April 2003).

\section{fungizone}

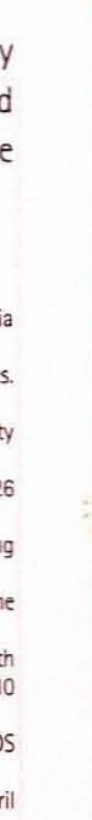

